\title{
Produção e avaliação da sobrevivência de estruturas de resistência de fungos fitopatogênicos habitantes do solo
}

\author{
César Júnior Bueno ${ }^{1 *}$, Márcia Michelle de Queiroz Ambrósio ${ }^{2,3}$, Nilton Luiz de Souza ${ }^{2}$
}

\begin{abstract}
${ }^{1}$ APTA/ Pólo Regional do Extremo Oeste - Av. Alcides Fagundes Chagas, 122, CEP 16055-240, Araçatuba/SP, Brasil. E-mail: cjbueno@aptaregional.sp.gov.br; ${ }^{2}$ Departamento de Produção Vegetal/Setor Defesa Fitossanitária, Faculdade de Ciências Agronômicas/Universidade Estadual Paulista, CP. 237, CEP 18603-970, Botucatu/SP, Brasil e Bolsista do CNPq; ${ }^{3}$ Aluna de Doutorado-Bolsista da Capes.

*Parte da tese de doutorado do primeiro autor realizada como bolsista da FAPESP.

Autor para correspondência: César Júnior Bueno.

Data de chegada: 12/01/2005. Aceito para publicação em: 23/05/2006.
\end{abstract}

\section{RESUMO}

Bueno, C.J.; Ambrósio, M.M. de Q.; Souza, N.L. Produção e avaliação da sobrevivência de estruturas de resistência de fungos fitopatogênicos habitantes do solo. Summa Phytopathologica, v.33, n.1, p.47-55, 2007.

Os fungos fitopatogênicos habitantes do solo causam grandes perdas em culturas econômicas. Estes organismos produzem estruturas de resistência na ausência de hospedeiros e/ou nas condições climáticas desfavoráveis. Isto permite a sobrevivência destes organismos no solo por longos períodos de tempo. A presença das estruturas de resistência inviabiliza o controle do patógeno.

O objetivo deste trabalho foi desenvolver metodologias para produzir e também para avaliar a sobrevivência das estruturas de resistência dos fungos Fusarium oxysporum f.sp. lycopersici raça 2, Macrophomina phaseolina, Rhizoctonia solani AG4 HGI, Sclerotium rolfsii, Sclerotinia sclerotiorum e Verticillium dahliae.
O delineamento experimental foi inteiramente casualizado, constituído por 6 fungos, 8 épocas de avaliação $(0,15,30,60,90$, 120, 150 e 180 dias do início do experimento) e duas condições: campo e laboratório. No campo, a $10 \mathrm{~cm}$ de profundidade, para cada época de avaliação, foram enterradas duas bolsas contendo estruturas de cada fungo. No laboratório, foram mantidos dois frascos para cada patógeno. O parâmetro avaliado foi a sobrevivência das estruturas dos fungos.

Constatou-se que todas as metodologias desenvolvidas refletiram de forma positiva quanto a sobrevivência dos fungos no campo e na avaliação dessa característica em condições de laboratório.

Palavras-chave adicionais: escleródios, clamidósporos, metodologias, fungos de solo.

\section{ABSTRACT}

Bueno, C.J.; Ambrósio, M.M. de Q.; Souza, N.L. Production and evaluation of survival of resistance structures of soilborne phytopathogenic fungi. Summa Phytopathologica, v.33, n.1, p.47-55, 2007.

Soilborne phytopathogenic fungi cause great losses in economical crops. These organisms produce resistance structures in the absence of hosts and / or under unfavorable climatic conditions. This allows the survival in soil for long period of time. When present, these structures make the pathogen control unfeasible.

The objective of this work was to develop methodologies to produce and evaluate the survival of the resistance structures of Fusarium oxysporum f.sp. lycopersici race 2, Macrophomina phaseolina, Rhizoctonia solani AG4 HGI, Sclerotium rolfsii, Sclerotinia sclerotiorum, and Verticillium dahliae.
The experiment was carried out in a randomized design, with 6 fungi per plot, 8 evaluation periods $(0,15,30,60,90,120,150$ and 180 days from the beginning of the experiment) and two conditions: field and laboratory. The structures of each fungus inside nylon bags (two replications) were buried in the field at $10 \mathrm{~cm}$ in depth for each evaluation, while in laboratory two flasks were maintained for each pathogen. The parameter evaluated was the fungal survival structures.

All the methodologies developed showed positive results as the survival of the fungi in the field as well as in the evaluation of survival in lab conditions.

Additional Keywords: sclerotia, chlamydospore, methodologies, soilborne fungi.

Os fungos fitopatogênicos habitantes do solo causam grandes perdas em culturas econômicas. Estes organismos produzem estruturas de resistência na ausência de hospedeiros e/ou nas condições climáticas desfavoráveis. Uma vez introduzidos em uma área cultivada, estes fungos constituem um problema de difícil controle, pois as suas estruturas sobrevivem no solo por vários 
anos como clamidósporos de Fusarium oxysporum (04), escleródios de Sclerotium rolfsii, Sclerotinia sclerotiorum, Rhizoctonia spp. $(2,14)$ e microescleródios de Macrophomina phaseolina e de Verticillium dahliae $(2,5)$.

A padronização e a repetibilidade de metodologias para trabalhar com as estruturas de resistência dos fungos fitopatogênicos habitantes do solo poderá ser uma ferramenta na geração de conhecimentos sobre esses organismos e na busca de novas alternativas de controle. Isto implicará também na não necessidade de se trabalhar com plantas hospedeiras e de se encontrar áreas infestadas naturalmente.

No presente trabalho, objetivou-se desenvolver metodologias para produzir e também para avaliar a sobrevivência das estruturas de resistência dos fungos Fusarium oxysporum f.sp. lycopersici raça 2, Macrophomina phaseolina, Rhizoctonia solani AG4 HGI, Sclerotium rolfsii, Sclerotinia sclerotiorum e Verticillium dahliae.

\section{MATERIAL E MÉTODOS}

O ensaio foi conduzido nas dependências do Departamento de Produção Vegetal/Defesa Fitossanitária da Faculdade de Ciências Agronômicas (FCA)/UNESP-Botucatu/SP.

$\mathrm{Na}$ micoteca da FCA/UNESP-Botucatu/SP foi obtido um isolado de cada um dos seguintes fungos: Fusarium oxysporum f.sp. lycopersici (Sacc.) Snyder \& Hansen raça 2, Macrophomina phaseolina (Tassi) Goindanich., Rhizoctonia solani Kühn AG 4 HGI, Sclerotium rolfsii Sacc., Sclerotinia sclerotiorum (Lib) de Bary e de Verticillium dahliae Kleb.

\section{Produção de estruturas de resistência}

\section{Fusarium oxysporum f.sp. lycopersici raça 2}

Seguiu-se a metodologia de Blok (6) modificada, que consistiu em multiplicar o fungo em extrato de malte líquido por 7 dias, no escuro, a $25^{\circ} \mathrm{C}$. Após o crescimento, a suspensão do fungo foi colocada em uma bandeja de alumínio, sem haver necessidade de qualquer procedimento, seguida da adição do pó de talco na proporção 2:1 (v/p). Esse material foi deixado para secar em estufa de circulação forçada de ar a $26^{\circ} \mathrm{C}$ por 14 dias.

\section{Macrophomina phaseolina}

Utilizou-se metodologia semelhante à adotada para $R$. solani, diferindo apenas na temperatura de incubação do fungo que foi de $32^{\circ} \mathrm{C}$.

\section{Rhizoctonia solani Kühn AG 4 HGI}

As estruturas de resistência do fungo foram produzidas em substrato-areno orgânico de forma semelhante a metodologia desenvolvida por Lefevre (25).

\section{Sclerotium rolfsii}

A produção de escleródios foi efetuada com a colocação de uma estrutura do fungo sobre a superfície de uma "fina" camada do meio de cultura BDA (Batata Dextrose Agar) + 0,05 mg/mL de oxitetraciclina, incubado em estufa tipo BOD a $25^{\circ} \mathrm{C}$, no escuro, por 30 dias.

\section{Sclerotinia sclerotiorum}

Os escleródios do fungo foram produzidos em substrato de fubáfeijão de forma semelhante a metodologia desenvolvida por Ferraz \& Café Filho (16).

\section{Verticillium dahliae}

A produção de microescleródios deste patógeno seguiu metodologia semelhante a utilizada para $R$. solani, diferindo no tempo e na temperatura de incubação do fungo que foram de 30 dias e $24^{\circ} \mathrm{C}$, respectivamente.

\section{Instalação do experimento}

O delineamento experimental foi inteiramente casualizado, constituído por 6 fungos, 7 épocas de avaliação $(0,15,30,60,90,120$, 150 e 180 dias do início do experimento) e duas condições: campo e laboratório. No campo, para cada época de avaliação, duas bolsas de náilon contendo estruturas de cada fungo foram identificadas e enterradas a $10 \mathrm{~cm}$ de profundidade no solo (Latossolo Vermelho Escuro fase arenosa) com espaçamento de 25 × $25 \mathrm{~cm}$ uma da outra. No laboratório, para cada época de avaliação, haviam dois frascos contendo as estruturas de resistência de cada fungo. Portanto, as amostras foram coletadas sempre do mesmo frasco. O parâmetro avaliado nas duas condições foi a sobrevivência das estruturas de resistência dos fungos.

\section{Avaliação da sobrevivência}

\section{Fusarium oxysporum f. sp. lycopersici raça 2}

Combinou-se parte da metodologia de Blok (6) e parte de Larkin et al. (24). Essa mistura de metodologias consistiu em efetuar três diluições seriada (1:10) de uma amostra (pó de talco+clamidósporos $10 \mathrm{~g})$ em solução salina $(0,85 \%$ de $\mathrm{NaCl})$ seguindo-se de plaqueamento de alíquotas $(0,1 \mathrm{~mL})$ sobre o meio semi-seletivo de Komada (23). As estruturas foram mantidas em estufa tipo BOD a $26^{\circ} \mathrm{C}$, no escuro, por 3-4 dias. Após a germinação das estruturas, efetuou-se a contagem das unidades formadoras de colônias (ufc) por grama de pó de talco. Foram feitas 4 repetições (placas) de cada uma das três diluições seriadas de cada amostra, sendo a amostra obtida de cada bolsa removida do campo e de cada frasco mantido no laboratório.

\section{Macrophomina phaseolina}

Procedeu-se a transferência do substrato areno-orgânico + microescleródios para uma nova bolsa de náilon e submeteu essas estruturas a uma desinfestação superficial com as seguintes etapas: rápida imersão em álcool $70^{\circ}, 20$ segundos em solução de hipoclorito de sódio a $0,5 \%$ e lavagens sucessivas em água destilada esterilizada. Transferiram-se porções do substrato+microescleródios para a superfície do meio semi-seletivo RB (12) modificado (39 g de BDA, $224 \mathrm{mg}$ i.a. de metalaxyl, $100 \mathrm{mg}$ de rifampicina e $1 \mathrm{~L}$ de água destilada). As estruturas foram mantidas em estufa tipo BOD a $32^{\circ} \mathrm{C}$, por $4-5$ dias, no escuro. As estruturas germinadas e com formação de colônias mais microescleródios (cor preta) foram avaliadas. Foram feitas 5 repetições (placas) por amostra de cada bolsa do campo e de cada frasco mantido no laboratório, sendo cada placa constituída por 10 porções do substrato+microescleródios.

\section{Rhizoctonia solani AG4 HGI}

Consistiu em transferir o substrato areno-orgânico+escleródios para uma nova bolsa de náilon com a desinfestação superficial passando pelas seguintes etapas: rápida imersão em álcool $70^{\circ}, 5$ segundos em solução de hipoclorito de sódio a $1 \%$ e lavagens sucessivas em água destilada esterilizada. Em seguida, foram transferidas porções do substrato+escleródios para a superfície do meio semi-seletivo de KHMP (22). As estruturas foram mantidas em estufa tipo BOD a $26^{\circ} \mathrm{C}$, no escuro, por 3-4 dias. Primeiramente, uma gota de lactofenol foi pingada sobre cada porção de substrato. Em seguida, com auxílio 
de microscópio estereoscópico, observou-se o micélio característico do patógeno, germinado a partir do substrato contendo escleródios, no meio de cultura. Foram feitas 5 repetições (placas) por amostra de cada bolsa do campo e de cada frasco mantido no laboratório, sendo cada placa constituída por 10 porções do substrato+escleródios.

\section{Sclerotium rolfsii}

Os escleródios, após serem colocados em uma nova bolsa de náilon, foram submetidos a desinfestação superficial passando pelas seguintes etapas, de acordo com a metodologia de Resende \& Zambolim (37) para Sclerotium cepivorum modificada: rápida imersão em álcool $70^{\circ}$, 1 minuto em solução de hipoclorito de sódio a $1,5 \%$ e lavagens sucessivas em água destilada esterilizada. Os escleródios desinfestados foram transferidos para a superfície do meio $\mathrm{BDA}+0,05 \mathrm{mg} / \mathrm{mL}$ de oxitetraciclina. As estruturas foram mantidas em estufa tipo BOD a $26^{\circ} \mathrm{C}$, no escuro, por 3-4 dias. As estruturas germinadas e com formação de micélio característico do patógeno foram avaliadas. Foram feitas 5 repetições (placas) por amostra de cada bolsa do campo e de cada frasco mantido no laboratório, sendo que cada placa continha 10 escleródios.

\section{Sclerotinia sclerotiorum}

Os escleródios foram transferidos para uma peneira de $1 \mathrm{~mm}$ de abertura e, em seguida, lavados com um jato de água de torneira por 5 minutos (33). Os escleródios lavados foram transferidos para uma nova bolsa de náilon e desinfestados superficialmente através dos seguintes passos: 1 minuto em álcool 50 e 3 minutos em solução de hipoclorito de sódio a 1\% (33). Após a desinfestação dos escleródios, estes foram transferidos para a superfície do meio de Neon $(33,41)$ e em seguida incubados em uma estufa tipo $\mathrm{BOD}$ a $18^{\circ} \mathrm{C}$, no escuro, por até 6 dias. A viabilidade dos escleródios foi constatada pela mudança da cor do meio de azul para amarelo claro (33). Foram feitas 5 repetições (placas) por amostra de cada bolsa do campo e de cada frasco mantido no laboratório, sendo cada placa constituída por 5 escleródios.

\section{Verticillium dahliae}

Consistiu em colocar o substrato+microescleródios em uma nova bolsa de náilon e mergulhar em água destilada esterilizada, visando umedecer o substrato para facilitar a transferência de porções para a superfície do meio semi-seletivo de Ausher et al. (3). As estruturas foram mantidas, inicialmente, em estufa tipo $\mathrm{BOD}$ a $18^{\circ} \mathrm{C}$, no escuro, por 3-4 dias. Após a germinação das estruturas, efetuou-se a contagem das porções contendo hifas do patógeno. Posteriormente, as estruturas foram mantidas na BOD, na mesma temperatura, até 30 dias, onde apareceu a formação de microescleródios nas bordas das colônias, aferindo a avaliação. Foram feitas 5 repetições (placas) por amostra de cada bolsa do campo e de cada frasco mantido no laboratório, sendo cada placa constituída por 10 porções do substrato+microescleródios.

\section{Análise estatística}

Realizou-se a análise não-paramétrica de Mann-Whitney do número de colônias de Fusarium, complementada com comparações múltiplas (39). Em relação à freqüência total de sobrevivência dos demais fungos, utilizou-se o teste de Goodman (20) para contrastes entre e dentro de populações multinomiais [no caso binomiais, sendo considerado como sucesso à presença (vivo) e fracasso a ausência (morto) dos fungos]. Todas as discussões foram realizadas ao nível de $5 \%$ de significância.

\section{RESULTADOS E DISCUSSÃO}

Sobrevivência das estruturas de cada fungo no campo e no laboratório

A precipitação registrada no período do experimento, que foi de março a setembro de 2002, consta na Figura 1.

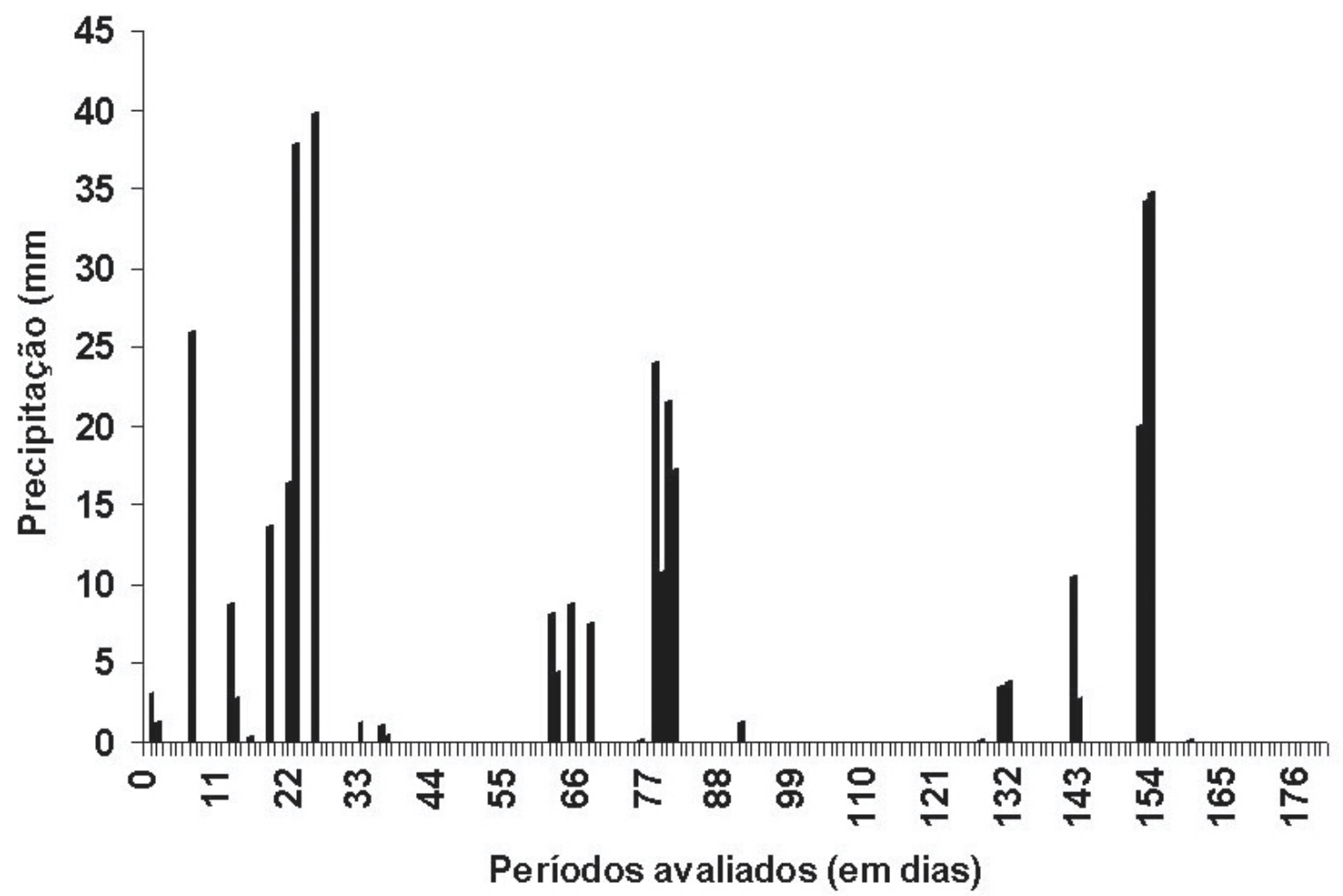

Figura 1. Precipitação diária registrada $(\mathrm{em} \mathrm{mm})$ no período do experimento. 
Tabela 1. Sobrevivência das estruturas dos fungos Macrophomina phaseolina, Rhizoctonia solani AG4 HGI, Sclerotium rolfsii, Sclerotinia sclerotiorum, Verticillium dahliae e Fusarium oxysporum f.sp. lycopersici raça 2 enterradas no campo e das mantidas em condições de laboratório, durante seis meses.

\begin{tabular}{|c|c|c|c|c|c|c|c|c|c|c|}
\hline \multirow[t]{2}{*}{ Tratamentos } & \multicolumn{8}{|c|}{ Períodos avaliados (os dois primeiros em dias e depois mensalmente) } & \multicolumn{2}{|c|}{ Análise estatística } \\
\hline & 0 & 15 & 01 & 02 & 03 & 04 & 05 & 06 & Vivos $^{1}$ & Mortos \\
\hline \multicolumn{11}{|c|}{ \% média de sobrevivência-Macrophomina phaseolina } \\
\hline Laboratório & 100 & 100 & 100 & 100 & 100 & 100 & 96 & 98 & 99,25 a ; 794 & $0,75 \mathrm{~b} ; 6$ \\
\hline \multicolumn{11}{|c|}{ \% média de sobrevivência - Rhizoctonia solani } \\
\hline Campo & 100 & 100 & 100 & 100 & 100 & 89 & 89 & 100 & $97,25 \mathrm{a} ; 778$ & $2,75 \mathrm{~b} ; 22$ \\
\hline \multicolumn{11}{|c|}{ \% média de sobrevivência - Sclerotium rolfsii } \\
\hline Campo & 100 & 100 & 100 & 100 & 100 & 100 & 100 & 100 & $100 \mathrm{a} ; 800$ & $0 \mathrm{a} ; 0$ \\
\hline Laboratório & 100 & 100 & 100 & 100 & 100 & 100 & 100 & 100 & $100 \mathrm{a} ; 800$ & $0 \mathrm{a} ; 0$ \\
\hline \multicolumn{11}{|c|}{ \% média de sobrevivência - Sclerotinia sclerotiorum } \\
\hline Campo & 100 & 79 & 84 & 84 & 92 & 97 & 95 & 95 & 90,75 a $; 726$ & $9,25 \mathrm{~b} ; 74$ \\
\hline Laboratório & 100 & 100 & 98 & 0 & 0 & 0 & 0 & 0 & $37,25 b ; 298$ & 62,75 a $; 502$ \\
\hline Campo & 3.375 & 23.750 & 74.125 & 137.625 & 243.000 & 13.713 & 278.750 & 94.500 & $674.500^{5}(27$. & $.230 .000) \mathrm{a}^{7}$ \\
\hline Laboratório & 3.375 & 463 & 0 & 0 & 0 & 0 & 0 & 0 & $0(0$ & ) $b$ \\
\hline
\end{tabular}

${ }^{1}$ Sobrevivência das estruturas dos fungos com contagem dos vivos e dos mortos;

${ }^{2}$ Porcentagem de sobreviventes: vivos e mortos. Média de 10 repetições;

${ }^{3}$ Freqüência de sobreviventes seguida de mesma letra na coluna não diferem entre si estatisticamente ao nível de $5 \%$ de probabilidade pelo teste de Goodman (1964);

${ }^{4}$ Soma das freqüências de sobreviventes (vivos e mortos) das estruturas dos fungos;

${ }^{5}$ Mediana. Média de 8 repetições;

${ }^{6}$ Semi-amplitude interquartílica com os valores mínimo e máximo;

${ }^{7}$ Mediana seguida de mesma letra na coluna não diferem entre si de acordo com comparações múltiplas de Siegel \& Castellan Jr. (1988) ao nível de 5\% de probabilidade.

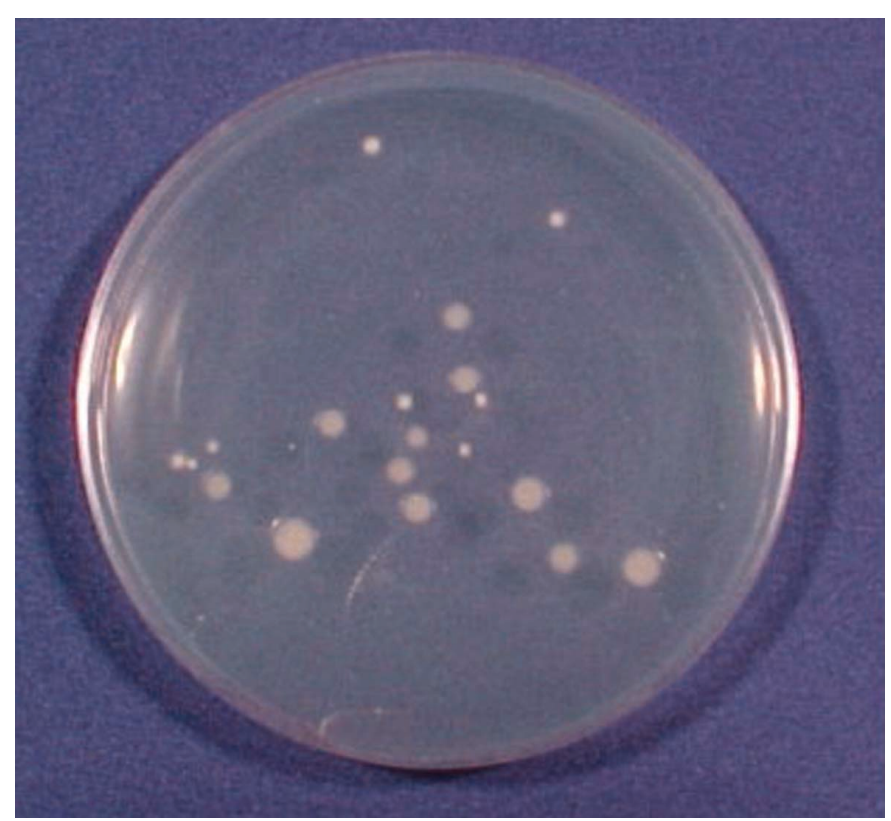

Figura 2. Unidades formadoras de colônias de Fusarium oxysporum f. sp. lycopersici raça 2 em meio de cultura semi-seletivo de Komada, originadas a partir de clamidósporos do fungo produzidos em pó de talco

\section{Fusarium oxysporum f.sp. lycopersici raça 2}

A metodologia de Blok (6) modificada para a produção de clamidósporos de Fusarium preservou a sobrevivência do fungo em condições de campo (Tabela 1).

De acordo com a Figura 2, constatou-se rapidez e praticidade na avaliação da sobrevivência dos clamidósporos de $F$. oxysporum f.sp. lycopersici raça 2.

No presente trabalho, observou-se que a produção de clamidósporos do fungo no pó de talco é dependente dos conídios formados inicialmente no meio líquido de extrato de malte. Há relatos também da produção de estruturas de resistência do fungo em pó de talco por Minuto et al. (32) e em meio de cultura acrescido de glicose ou de carbonato de magnésio por Windels (47).

O número médio de clamidósporos foi maior quando houve aumento no teor de umidade do solo (Figura 1 e Tabela 1), o que explica a oscilação do número de sobreviventes do fungo no campo. Segundo Lockwood (26), na presença de umidade, as estruturas de resistência de $F$. oxysporum germinam e o micélio produz novos clamidósporos. Uma outra explicação para tal oscilação no número médio de clamidósporos está no fato do fungo sintetizar uma proteína nessas estruturas (18), ativada por condições de estresse ambiental no solo, como altas temperaturas, garantindo dessa forma a sobrevivência variada do fungo.

A metodologia desenvolvida no presente trabalho para este fungo 
já foi utilizada por Souza \& Bueno (40) em condições de campo e por Bueno et al. (08) em condições de microcosmo. Nos trabalhos de Souza \& Bueno (40) e de Bueno et al. (08), o objetivo comum foi verificar o controle das estruturas de resistência do fungo utilizando a técnica de solarização combinada com a prévia incorporação de couve. Os resultados do presente trabalho e os de Souza \& Bueno (40) e de Bueno et al. (8) atestam a eficiência da metodologia desenvolvida para produzir e avaliar a sobrevivência de clamidósporos do fungo.

\section{Macrophomina phaseolina}

Com base nos resultados da Tabela 1, verificou-se a preservação das estruturas de resistência de $M$. phaseolina, produzidas com a adaptação da metodologia de Lefevre (25), tanto no campo como no laboratório.

A soma das freqüências de sobrevivência dos microescleródios do fungo foi maior em condições de laboratório do que em campo (Tabela 1). A diferença entre os tratamentos não implica em inviabilizar o uso da metodologia desenvolvida para o fungo no campo, pois essa variação ocorreu, provavelmente, devido ao controle das estruturas por antagonistas e ao aumento na umidade do solo neste período (Figura 1). Esse fungo ocorre em solo com deficiência hídrica.

Na Figura 3 pode ser observada a facilidade e a rapidez do método empregado para avaliar a sobrevivência das estruturas do fungo.

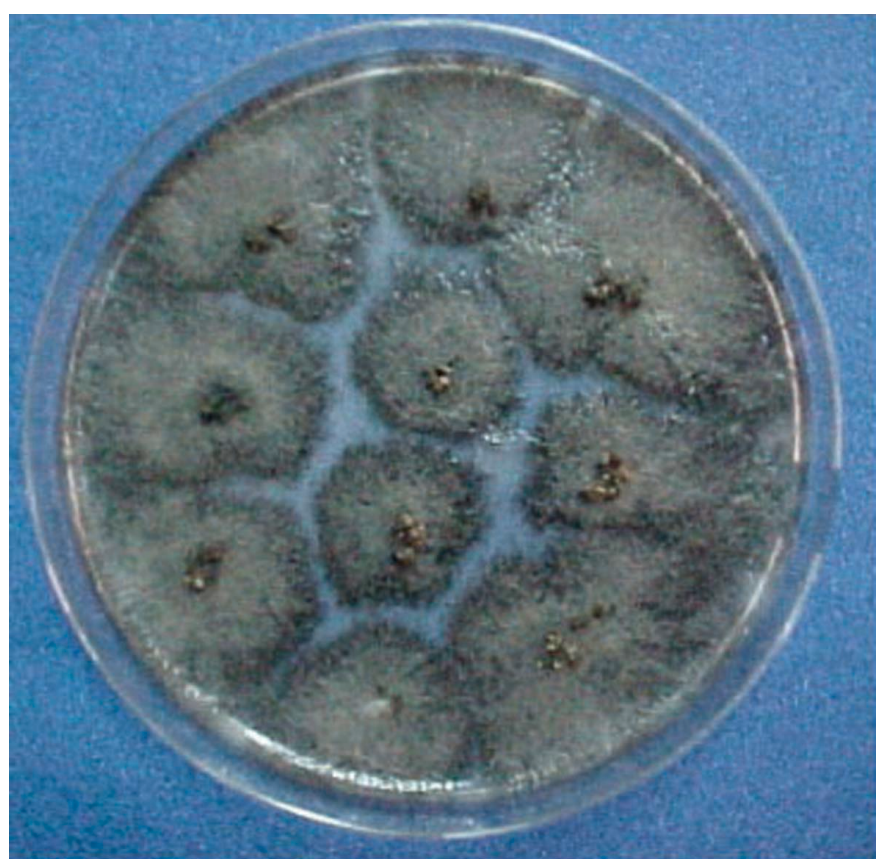

Figura 3. Colônias de Macrophomina phaseolina em meio de cultura semi-seletivo RB modificado apresentando formação de microescleródios (cor preta), originadas a partir de estruturas do fungo produzidas em substrato areno-orgânico.

Para este patógeno, há relatos da utilização do meio RB para isolamento do patógeno do solo (12). Entretanto, as metodologias para produção e para avaliação da sobrevivência de microescleródios do fungo e a modificação do meio semi-seletivo foram desenvolvidas no presente trabalho.

Olaya et al. (34) produziram microescleródios de M. phaseolina em palito de madeira inserido em meio de BDA, enquanto que Coelho Netto \& Dhingra (13) e Mihail (30) em areia + farinha de milho. Grande produção de estruturas do fungo pode ser obtida em meio de
BDA gelatinoso (45), em meio de Prosopis juliflora-Batata (27) e em meio líquido de sementes de soja + sacarose (38).

A metodologia de produção de estruturas de M. phaseolina adaptada de Lefevre (25) não implicou na separação dos microescleródios do meio de produção como descreveram Viana (45) e Mihail (30), o que facilitou o transporte das estruturas para o campo.

A avaliação da sobrevivência do fungo pela metodologia proposta foi prática, rápida e segura, uma vez que possibilitou observar a emergência do micélio e, ainda, a visualização da formação de microescleródios nas colônias no meio RB modificado, facilitando a avaliação. Mihail (30) relatou desinfestação superficial de amostras de solo, em solução de hipoclorito a $0,525 \%$ por 10 minutos, seguindose de plaqueamento de alíquotas sobre o meio semi-seletivo de M. A avaliação da sobrevivência das estruturas do fungo foi a mesma descrita no trabalho de Mihail (30). Viana (45) observou apenas a emergência do micélio dos microescleródios, em microscópio ótico, em uma membrana de celulose acoplada em um sistema chamado FAM. Lodha et al. (27), após coletar amostra de solo infestado artificialmente com M. phaseolina e obter estruturas individualizadas, plaquearam os microescleródios sobre o meio ágar-cloroneb-mercúrio-rosa bengal. Olaya et al. (34) avaliaram a sobrevivência do fungo por meio da desinfestação de palitos de madeira recuperados do solo, contendo estruturas de $M$. phaseolina, em solução de hipoclorito de sódio a $1 \%$ por 1 a 2 minutos, seguindo-se de plaqueamento dos palitos desinfestados em meio de BDA acidificado.

A metodologia desenvolvida no presente trabalho para este fungo já foi utilizada por Ambrósio et al. (01) em condições de campo e por Bueno et al. (08) em condições de microcosmo. Nos trabalhos de Ambrósio et al. (01) e de Bueno et al. (08), o objetivo comum foi verificar o controle das estruturas do fungo utilizando a técnica de solarização combinada com a prévia incorporação de brássica. Os resultados do presente trabalho e os de Ambrósio et al. (01) e de Bueno et al. (08) atestam a eficiência da metodologia desenvolvida para produzir e avaliar a sobrevivência de microescleródios do fungo.

\section{Rhizoctonia solani AG4 HGI}

De acordo com os dados da Tabela 1, observou-se que as estruturas do fungo, produzidas através da metodologia de Lefevre (25), sobreviveram no solo do campo.

A soma das freqüências de sobrevivência de escleródios do fungo foi maior no campo do que no laboratório (Tabela 1). As estruturas mantidas em condições de laboratório morreram após 4 meses, inviabilizando a utilização desta metodologia nesta condição.

$\mathrm{Na}$ Figura 4, notou-se a praticidade e a rapidez na avaliação da sobrevivência das estruturas do fungo pela metodologia proposta no presente trabalho.

A metodologia de produção das estruturas de $R$. solani e o meio KHMP já foram relatados na literatura $(10,22,25)$. Entretanto, a metodologia empregada para avaliar a sobrevivência do fungo foi desenvolvida no presente trabalho.

Escleródios deste patógeno podem ser produzidos também em arroz em casca autoclavado (42), em grãos verdes de feijão autoclavados (21), em pedaços de casca de amendoim e sementes com adição de sacarose (10) e em perlita esterilizada embebida com extrato de malte + peptona (06).

A desinfestação superficial do substrato areno-orgânico + escleródios do fungo, no presente trabalho, diferiu de Carling e Summner (10), que citaram uma outra seqüência de assepsia mas em tecidos de plantas. Blok (06) avaliou a sobrevivência do fungo por meio da contagem do crescimento de hifas por perlita colocada sobre o meio de 


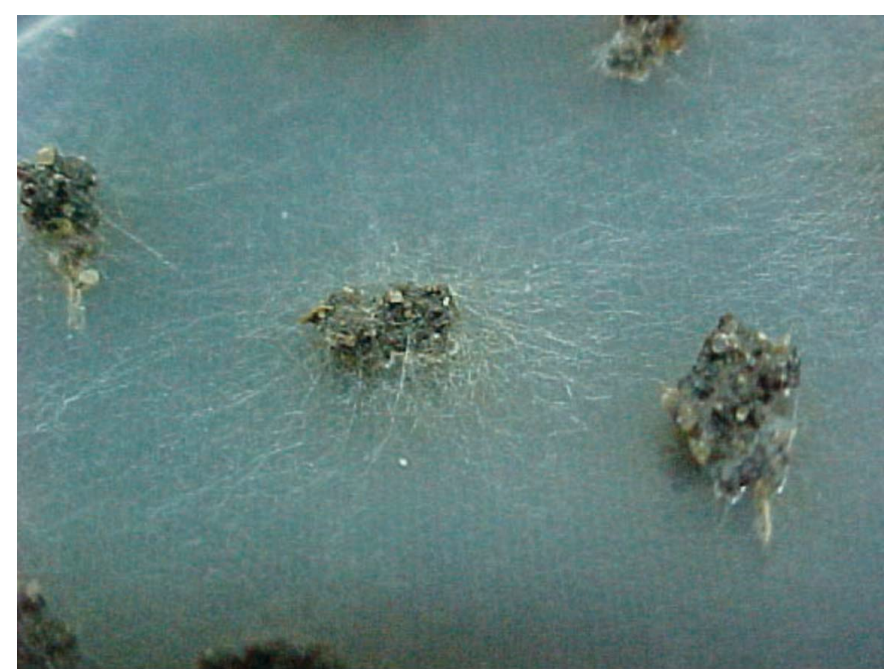

Figura 4. Colônias de Rhizoctonia solani AG4 HGI em meio de cultura semi-seletivo KHMP, originadas a partir de escleródios do fungo produzidos em substrato areno-orgânico.

ágar-água a $1,2 \%$ com $50 \mu \mathrm{g} . \mathrm{mL}^{-1}$ de oxitetraciclina a $20^{\circ} \mathrm{C}$. Os dados do número de hifas crescidas são colocados em uma fórmula para determinar o índice de germinação do patógeno.

No presente trabalho, a avaliação do crescimento micelial do fungo, em meio KHMP, com hifas coradas com lactofenol e emergidas a partir do substrato areno-orgânico, foi feita sob microscópio estereoscópico.

Segundo relatou Márcia Michelle de Queiroz Ambrósio (comunicação pessoal), que utilizou a presente metodologia desenvolvida para este fungo na sua tese de doutorado, a mesma foi eficiente.

\section{Sclerotium rolfsii}

A metodologia desenvolvida para produção de estruturas de resistência do fungo, possibilitou a sobrevivência das mesmas tanto em condições de campo quanto de laboratório (Tabela 1).

De acordo com os dados da Tabela 1, constatou-se que ambos os tratamentos não diferiram entre si quanto à soma das freqüências de sobrevivência de escleródios do fungo, assegurando a utilização da metodologia desenvolvida para as duas condições dos tratamentos.

Como pode ser visto na Figura 5, o método facilitou a avaliação da sobrevivência dos escleródios do fungo de maneira rápida e prática.

Mihail \& Alcorn (31) relataram também a utilização do meio de BDA, mas sem adição de antibiótico para produção de escleródios do fungo. Para este patógeno, há relatos também de produção de estruturas em grãos de arroz (28), em hastes de feijão do cultivar Rosinha (11) e em substrato areno-orgânico (25).

No presente trabalho, o meio de produção de escleródios, BDA $+0,05 \mathrm{mg} / \mathrm{mL}$ de oxitetraciclina, foi também utilizado para a avaliação da sobrevivência do fungo. Essa metodologia diferiu da descrita por Lefevre (25), que citou no seu trabalho a produção de estruturas do fungo em substrato areno-orgânico e plaqueamento das mesmas, sem desinfestação superficial, em meio de BDA+oxitetraciclina, observando a emergência do micélio para obter a temperatura letal do patógeno.

O tempo de exposição dos escleródios do fungo na solução de hipoclorito de sódio a 1,5\%, no presente trabalho, diferiu de Resende \& Zambolim (37) para as estruturas de S. cepivorum. Mihail \& Alcorn (31) relataram desinfestação de escleródios de $S$. rolfsii por 1 a 2 minutos em solução de hipoclorito de sódio a $0,525 \%$ e plaqueamento

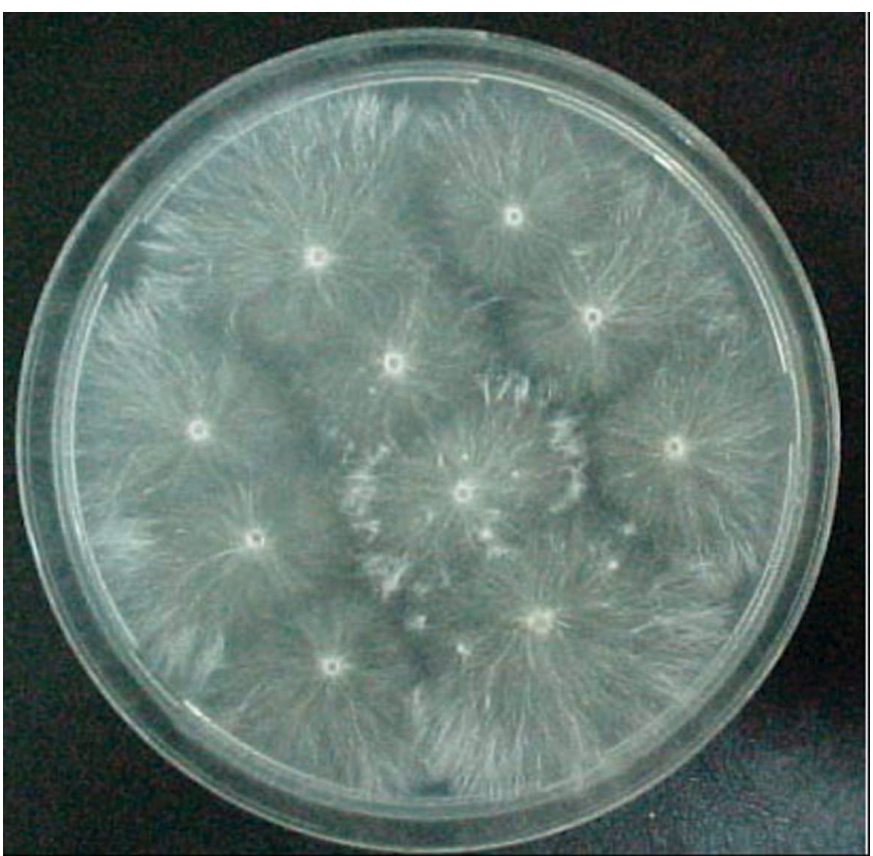

Figura 5. Colônias de Sclerotium rolfsii em meio de cultura contendo Batata Dextrose Ágar (BDA) + oxitetraciclina, originadas a partir de escleródios do fungo produzidos no mesmo meio de cultura.

das estruturas em meio BDA + sulfato de estreptomicina.

A metodologia proposta neste trabalho para $S$. rolfsii foi de fácil manuseio e segura para qualquer ambiente, diferindo de Punja \& Rahe (36) que citaram a inviabilização da técnica de peneiramento sob jato de água para isolar escleródios de $S$. cepivorum de solos texturizados e com alto teor de matéria orgânica.

Para isolados que produzem pequenos escleródios, dificultando o manuseio dos mesmos, pode-se tentar a produção das estruturas em substrato areno-orgânico, assim como relatado por Lefevre (25). No entanto, é necessário também desenvolver metodologia para avaliar a sobrevivência das estruturas do fungo produzidas com a metodologia de Lefevre (25).

A metodologia do presente trabalho desenvolvida para este fungo já foi utilizada por Souza \& Bueno (40) em condições de campo e por Bueno et al. (08) em condições de microcosmo. Nos trabalhos de Souza \& Bueno (40) e de Bueno et al. (08), o objetivo comum foi verificar o controle das estruturas do fungo utilizando a técnica de solarização combinada com a prévia incorporação de couve. Os dados gerados no presente trabalho e os de Souza \& Bueno (40) e de Bueno et al. (08) comprovam a eficiência da metodologia desenvolvida para produzir e avaliar a sobrevivência de escleródios do fungo.

\section{Sclerotinia sclerotiorum}

Com base nos resultados da Tabela 1, verificou-se que os escleródios individualizados de $S$. sclerotiorum podem ser enterrados no campo, pois permaneceram viáveis, assegurando a eficiência da metodologia de Ferraz \& Café Filho (16) para a produção de estruturas do fungo.

A soma das freqüências de sobrevivência de escleródios do fungo foi maior no campo do que no laboratório (Tabela 1). As estruturas mantidas em condições de laboratório morreram após um mês, inviabilizando a utilização desta metodologia nesta condição.

De acordo com o trabalho de Nasser et al. (33) e como pode ser visto pela Figura 6, o método permite a avaliação rápida e segura da sobrevivência do fungo, pois a estrutura quando viável muda a cor do 


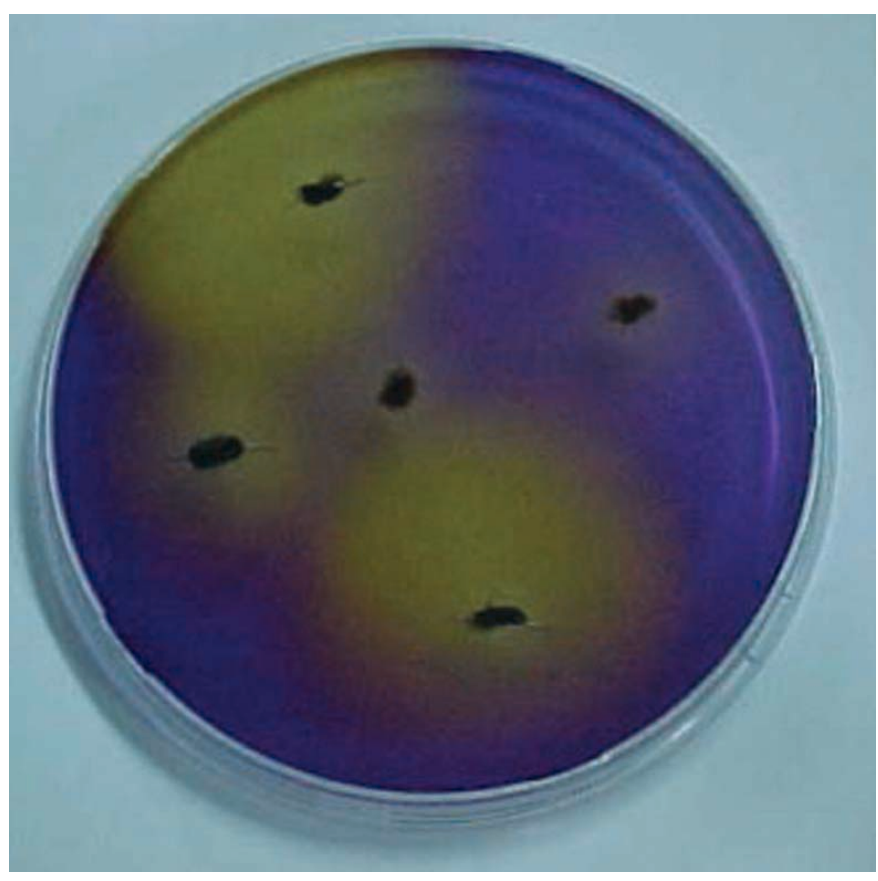

Figura 6. Colônias (cor amarela) de Sclerotinia sclerotiorum em meio de cultura semi-seletivo de Neon (cor azul), originadas a partir de escleródios do fungo produzidos em substrato de fubá-feijão.

meio de azul para amarelo.

Nasser et al. (33) relataram grande produção de escleródios deste fungo em cenouras autoclavadas, enquanto Tokeshi et al. (44) e Viana et al. (46) verificaram produção das estruturas do fungo em grãos de trigo e em substrato contendo areia + quirera de milho, respectivamente. Pratt (35) também citou a produção de escleródios de S. sclerotiorum utilizando substrato orgânico com feijão, vagem, pecíolos, discos de cenoura e pequenos grãos autoclavados em placa de Petri ou em frascos.

A desinfestação dos escleródios do fungo seguiu os passos citados por Nasser et al. (33), diferindo da seqüência de assepsia das estruturas do fungo relatada por Ferraz (15).

A metodologia para este fungo consistiu-se simplesmente da união de metodologias já desenvolvidas por Ferraz \& Café Filho (16), Ferraz (15) e Nasser et al. (33). De acordo com os dados da Tabela 1 e Figura 6 do presente trabalho mais os relatos de Ferraz \& Café Filho (16), Ferraz (15) e Nasser et al. (33), a metodologia para este fungo é eficiente para condições de campo.

\section{Verticillium dahliae}

Os microescleródios do fungo, produzidos com a metodologia desenvolvida, sobreviveram tanto no campo como no laboratório, durante o período estudado (Tabela 1).

A avaliação dos dados da Tabela 1 para o fungo V. dahliae, conduz às mesmas conclusões dos dados para o fungo $S$. rolfsii quanto à soma das freqüências de sobrevivência das estruturas de resistência.

De acordo com a Figura 7, notou-se a facilidade e a rapidez na avaliação da sobrevivência dos microescleródios do patógeno pela metodologia empregada no presente trabalho.

Não há na literatura nenhuma metodologia como a desenvolvida neste trabalho para esse fungo, apenas a citação do meio semi-seletivo para isolar o patógeno do solo (03).

Blok (06) obteve microescleródios de $V$. dahliae por meio da trituração de caules de batata densamente cobertos com as estruturas, enquanto Francl et al. (17) produziram as mesmas estruturas do fungo

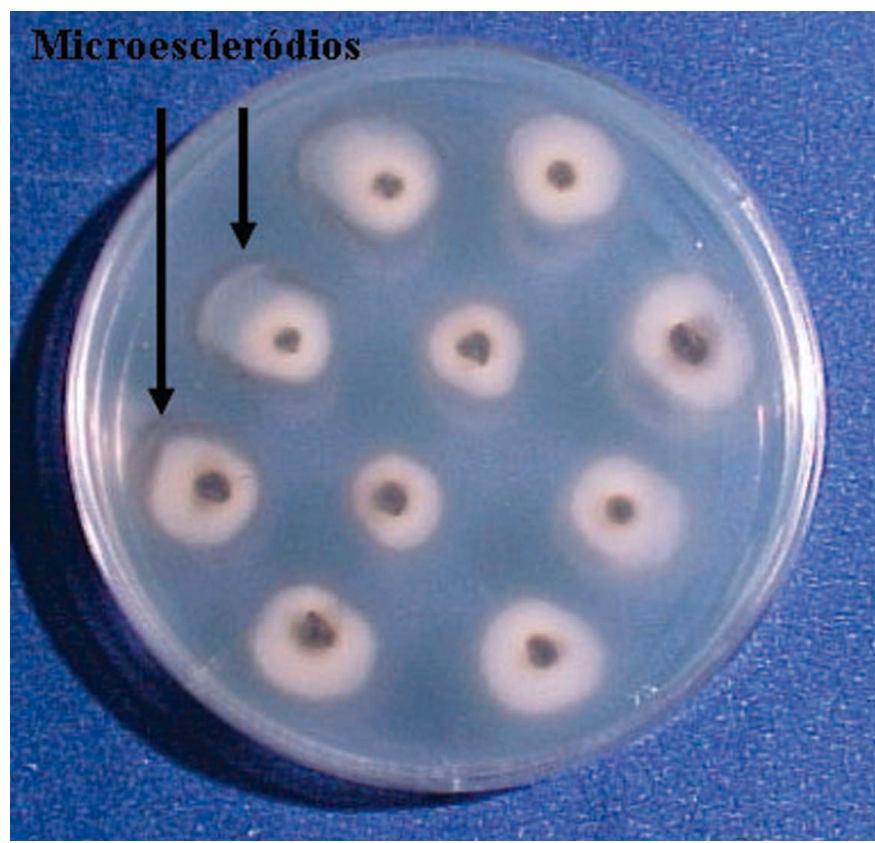

Figura 7. Colônias de Verticillium dahliae em meio de cultura semiseletivo de Ausher apresentando formação de microescleródios nas bordas, originadas a partir de estruturas do fungo produzidas em substrato arenoorgânico.

primeiramente em um meio mínimo para depois transferir para o solo e com isso obter inóculo para a realização de trabalhos. Para testar a técnica de solarização visando controlar $V$. dahliae em campo, Ghini et al. (19) infestaram artificialmente uma área experimental com inóculo do fungo produzido em milho pipoca.

Pela metodologia desenvolvida no presente trabalho não se verificou a necessidade de utilizar plantas hospedeiras (09) e, também, determinar a população do patógeno no solo $(07,29)$. Termorshuizen et al. (43) afirmaram que metodologias de determinação da população do patógeno no solo não são confiáveis.

As estruturas do fungo não passaram por uma desinfestação superficial, segundo a metodologia empregada no presente trabalho, contradizendo uma citação de Melouk (29). Blok (06) avaliou a sobrevivência do fungo por meio de peneiramento de inóculo (estruturas+solo) e ressuspensão das estruturas em ágar-água a $0,08 \%$ seguido de plaqueamento de alíquotas em extrato de solo com agar. Francl et al. (17), após efetuar diluição seriada de uma amostra (solo+estruturas), plaquearam alíquotas sobre o meio de álcool + estreptomicina, com o objetivo de verificar a sobrevivência do fungo.

Em qualquer lugar, pesquisas com os fitopatógenos estudados, poderão ser realizadas devido a padronização e a repetibilidade das metodologias desenvolvidas neste trabalho. Essas pesquisas, acreditando que sejam voltadas para a busca de novas alternativas para o controle destes patógenos, contarão com a não necessidade de se trabalhar com plantas hospedeiras e de não ser preciso encontrar áreas naturalmente infestadas.

\section{REFERÊNCIAS BIBLIOGRÁFICAS}

1. Ambrósio, M.M. de Q.; Bueno, C.J.; Souza, N.L. de. Sobrevivência de Macrophomina phaseolina em solo incorporado com brócolos seguido de solarização. Summa Phytopathologica, Botucatu, v.30, n.3, p.364-370, 2004

2. Amorin, L. Sobrevivência do inóculo. In: Bergamin Filho, A.; Kimati, 
H.; Amorin, L. (Ed.). Manual de fitopatologia. São Paulo: Agronômica Ceres, 1995. p.246-267.

3. Ausher, R.; Katan, J.; Ovadia, S. An improved selective medium for the isolation of Verticillium dahliae. Phytoparasitica, Rehovot, v.3, n.2, p.133-137, 1975.

4. Beckman, C.H. The nature of wilt diseases of plants. St. Paul: American Phytopathological Society Press. 1987.

5. Bianchini, A.; Maringoni, A.C.; Carneiro, S.M.T.P.G. Doenças do feijoeiro. In: Kimati, H. et al. (Ed). Manual de fitopatologia: doenças das plantas cultivadas. São Paulo: Agronômicas Ceres, 1997. p.376399

6. Blok, W. J. Early decline of asparagus in the Netherlands: etiology, epidemiology and management. 1997. 177f. Thesis (PhD) Wageningen Agricultural University, Wageningen.

7. Bourbos, V. A.; Skoudridakis, M. T. Soil solarization for the control of Verticillium wilt of greenhouse tomato. Phytoparasitica, Rehovot, v.24, n.4, p. 277-280, 1996.

8. Bueno, C.J.; Ambrósio, M.M. de Q.; Souza, N.L. Controle de Fusarium oxysporum f.sp. lycopersici raça 2, Macrophomina phaseolina e Sclerotium rolfsii em microcosmo simulando solarização com prévia incorporação de couve (Brassicae oleracea var. acephala L.). Summa Phytopathologica, Botucatu, v.30, n.3, p.356-363, 2004.

9. Bueno, C.J.; Masuda, Y.; Azevedo, F.A.; Aguillera, M.M.; Souza, N.L. Efeito direto e residual da solarização do solo no controle de Verticillium dahliae e de plantas infestantes na cultura da berinjela (Solanum melongena L.) em campo naturalmente infestado. Summa Phytopathologica, Jaboticabal, v.26, n.4, p.445-450, 2000.

10. Carling, D.E.; Sumner, D.R. Rhizoctonia. In: Singleton, L.L.; Mihail, J.D.; Rush, C.M. (Ed.). Methods for research on soilborne phytopathogenic fungi. St. Paul: The American Phytopathological Society, 1992. p.157-165

11. Chaves, K.C.; Costa, J.L. da S. Influência do método de inoculação e da quantidade de inóculo de Sclerotium rolfsii na severidade de podridão do colo do feijoeiro. Summa Phytopathologica, Jaboticabal, v.25, n.4, p.298-302, 1999.

12. Cloud, G.L. Comparison of three media for enumeration of sclerotia of Macrophomina phaseolina. Plant Disease, St. Paul, v.75, n.8, p.771-772, 1991.

13. Coelho Netto, R.A.; Dhingra, O.D. Method for evaluating bean genotype reaction to Macrophomina phaseolina. Fitopatologia Brasileira, Brasília, v.21, n.3, p.236-242, 1996.

14. Cooley-Smith, J.R.; Cook, R.C. Survival and germination of fungal sclerotia. Annual Review of Phytopathology, Palo Alto, v.9, p.6592, 1971

15. Ferraz, L. C. L. Práticas culturais para o manejo de mofobranco (Sclerotinia sclerotiorum) em feijoeiro. 2001. 154f. Tese (Doutorado em Agronomia/Fitopatologia) - Escola Superior de Agricultura "Luiz de Queiroz", Universidade de São Paulo, Piracicaba.

16. Ferraz, L. C. L.; Café Filho, A. C. Efeito da adição de fubá no meio de produção de escleródios e outros fatores influenciando na formação de apotécios de Sclerotinia sclerotiorum. Fitopatologia Brasileira, Brasília, v.23, n.3, p.364-369, 1998.

17. Francl, L.J.; Rowe, R.C.; Riedel, R.M.; Madden, L.V. Effects of three soil types on potato early dying disease and associated yield reduction. Phytopathology, St. Paul, v.78, n.2, p.159-166, 1988.

18. Freeman, S.; Ginzburg, C.; Katan, J. Heat shock protein synthesis in propagules of Fusarium oxysporum f.sp. niveum. Phytopathology, St. Paul. v.79, n.10, p.1054-1058, 1989.

19. Ghini, R.; Bettiol, W.; Souza, N. L. Solarização do solo para o controle de Verticillium dahliae em berinjela. Fitopatologia Brasileira, Brasília, v.17, n.4, p.384-388, 1992.

20. Goodman, L.A. Simultaneous confidence intervals for contrasts among multinomial populations. Annals of Mathematical Statistics, Beachwood, v.35, n.2, p.716-725, 1964.

21. Keinath, A.P.; Farnham, M.W. Differential cultivars and criteria for evaluating resistance to Rhizoctonia solani in seedling Brassica oleracea. Plant Disease, St. Paul, v.81, n.8, p.946-952, 1997.

22. Ko, W.; Hora, F.K. A selective medium for Rhizoctonia solani in soil. Phytopathology, St. Paul, v.61, n.6, p.707-710, 1971.

23. Komada, H. Development of a selective medium for quantitative isolation of Fusarium oxysporum from natural soil. Review of Plant
Protection Research, Tokyo, v.8, p.114-124, 1975.

24. Larkin, R.P.; Hopkins, D.L.; Martin, F.N. Ecology of Fusarium oxysporum f. sp. niveum in soils suppressive and conducive to Fusarium wilt of watermelon. Phytopathology, St. Paul, v.83, n.10, p.11051116,1993

25. Lefevre, A. F. V. Determinação da temperatura letal para $R h i$ zoctonia solani Kühn e Sclerotium rolfsii Sacc. e efeitos da solarização sobre algumas variáveis do solo. 1990. 94f. Dissertação (Mestrado em Agronomia/Proteção de Plantas) - Faculdade de Ciências Agronômicas, Universidade Estadual Paulista, Botucatu.

26. Lockwood, J.L. Curso avançado sobre fitopatógenos do solo. Piracicaba: Universidade de São Paulo, 1977. 41p.

27. Lodha, S.; Sharma, S.K.; Aggarwal, R.K. Solarization and natural heating of irrigated soil amended with cruciferous residues for improved control of Macrophomina phaseolina. Plant Pahology, London, v.46, n.2, p.186-190, 1997.

28. Matsumoto, M.N.; Homechin, M.; Massola Jr., N.S.; Kamikoga, A.T.M. Efeito do substrato de cultivo na produção de escleródios e na patogenicidade de Sclerotium rolfsii. Summa Phytopathologica, Jaboticabal, v.26, n.1, p.91-94, 2000.

29. Melouk, H.A. Verticillium. In: Singleton, L.L., Mihail, J.D., Rush, C.M. (Ed.). Methods for research on soilborne phytopathogenic fungi. St. Paul: The American Phytopathological Society, 1992. p. $175-178$.

30. Mihail, J.D. Macrophomina. In: Singleton, L.L., Mihail, J.D., Rush, C.M. (Ed). Methods for research on soilborne phytopathogenic fungi. St. Paul: The American Phytopathological Society, 1992. p.134-136.

31. Mihail, J.D.; Alcorn, S.M. Effects of soil solarization on Macrophomina phaseolina and Sclerotium rolfsii. Plant Disease, St. Paul, v.68, n.2, p.156-159, 1984.

32. Minuto, A.; Minuto, G.; Migheli, Q.; Mocioni, M.; Lodovica Gullino, M. Effect of antagonistic Fusarium spp. and different commercial biofungicide formulations on Fusarium wilt of basil (Ocimum basilicum L.). Crop Protection, Oxford, v.16, n.8, p.765-769, 1997.

33. Nasser, L.C.B.; Boland, G.J.; Sutton, J.C. Meio de cultura semiseletivo para detecção da viabilidade dos escleródios de Sclerotinia sclerotiorum. Fitopatologia Brasileira, Brasília, v.20, Supl., p.376, 1995. (Resumo).

34. Olaya, G.; Abawi, G.S.; Barnard, J. Influence of water potential on survival of sclerotia in soil and on colonization of bean stem segments by Macrophomina phaseolina. Plant Disease, St. Paul, v.80, n.12, p.1351-1354, 1996.

35. Pratt, R. G. Sclerotinia. In: Singleton, L. L.; Mihail, J. D.; Rush, C. M (Ed.). Methods for research on soilborne phytopathogenic fungi. St. Paul: The American Phytopathological Society, 1992. p.7478.

36. Punja, Z.K.; Rahe, J.E. Sclerotium. In: Singleton, L.L.; Mihail, J.D.; Rush, C.M. (Ed.). Methods for research on soilborne phytopathogenic fungi. St. Paul: The American Phytopathological Society, 1992. p.166-170.

37. Resende, M.L.V.; Zambolim, L. Eficiência de métodos utilizados para quantificação da população de escleródios de Sclerotium cepivorum Berk. no solo. Fitopatologia Brasileira, Brasília, v.11, n.3, p.493500,1986

38. Shurtleff, M.C.; Averre III, C.W. The plant disease clinic and field diagnosis of abiotc diseases. St. Paul: The American Phytopathological Society, 1997. 245p.

39. Siegel, S.; Castellan Jr., N. J. Non parametric statistics for the behavioral sciences. 2. ed. New York: McGraw-Hill, 1988. 312p.

40. Souza, N. L.; Bueno, C. J. Controle de clamidósporos de Fusarium oxysporum f.sp. lycopersici raça 2 e escleródios de Sclerotium rolfsii em solo solarizado incorporado com matéria orgânica. Summa Phytopathologica, Botucatu, v.29, n.2, p.153-160, 2003

41. Steadman, J.R.; Marcinkowska, J.; Rutledge, A. Semi-selective medium for isolation of Sclerotinia sclerotiorum. Canadian Journal of Plant Pathology, Guelph, v.16, n.1, p.68-70, 1994.

42. Suguino, E.; Maringoni, A.C. Comportamento de variedades de feijoeiro a Rhizoctonia solani. Summa Phytopathologica, Jaguariúna, v.21, n.2, p.124-126, 1995. 
43. Termorshuizen, A. et al. Interlaboratory comparison of methods to quantify microsclerotia of Verticillium dahliae in soil. Applied-Environmental-Microbiology, Washington, v.64, n.10, p.3846-3853, 1998.

44. Tokeshi, H.; Alves, M.C.; Sanches, A.B.; Harada, D.Y. Control of Sclerotinia sclerotiorum with effective microorganisms. Summa Phytopathologica, Jaboticabal, v.23, n.2, p.146-154, 1997.

45. Viana, F. M. P. Influência de fatores físicos e de material orgânico na germinação de microescleródios de Macrophomina phaseolina (Tassi) Goindanich. 1996. 100f. Tese (Doutorado em
Agronomia/Proteção de Plantas) - Faculdade de Ciências Agronômicas, Universidade Estadual Paulista, Botucatu.

46. Viana, F. M. P. et al. Controle do tombamento de plântulas de feijoeiro causada por Sclerotinia sclerotiorum com a incorporação de matéria orgânica ao substrato. Summa Phytopathologica, Jaboticabal, v.26, n.1, p.94-97, 2000.

47. Windels, C.E. Fusarium. In: Singleton, L.L.; Mihail, J.D.; Rush, C.M. (Ed.). Methods for research on soilborne phytopathogenic fungi. St. Paul: The American Phytopathological Society, 1992. p.115128 